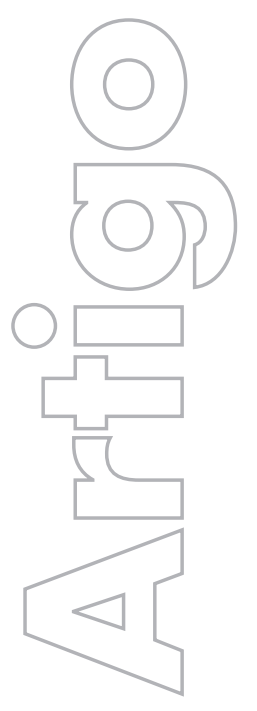

revista

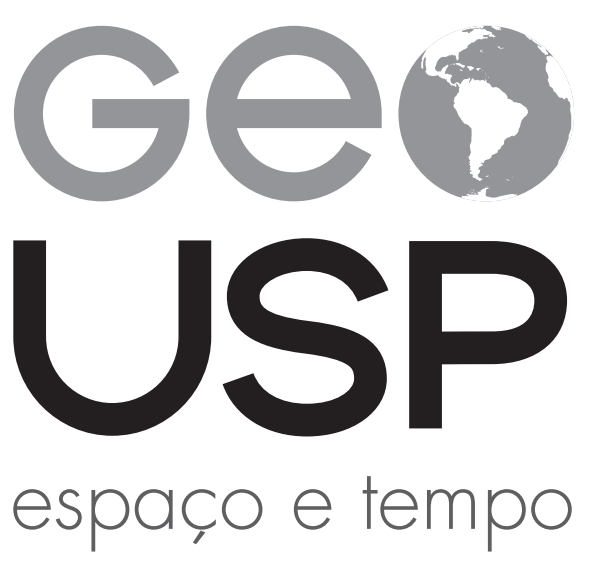

Volume $20 \bullet n^{\circ} 2(2016)$

\section{A dendeicultura na Amazônia paraense}

\author{
João Santos Nahum \\ UFPA
}

Cleison Bastos dos Santos

p. $281-294$

Como citar este artigo:

NAHUM, J. S.; SANTOS, C. B. A dendeicultura na Amazônia paraense. Geousp - Espaço e Tempo (Online), v. 20, n. 2, p. 281-294, mês. 2016. ISSN 2179-0892.

Disponível em: <http://www.revistas.usp.br/geousp/issue/ view/6465>. doi: http://dx.doi.org/10.11606/issn.2179-0892. geousp.2014.84539.

\section{(c) $(1) \Theta$}

Este artigo está licenciado sob a Creative Commons Attribution 4.0 License. 


\title{
A dendeicultura na Amazônia paraense
}

\section{Resumo}

Analisamos a expansão da dendeicultura na microrregião de Tomé-Açu, na Amazônia paraense. Em que transformações da paisagem, da configuração espacial, da dinâmica social, enfim, do território, podemos identificar esse boom? Partimos do território usado, o que nos permite considerar a dendeicultura um evento e afirmar que estamos diante de um boom do dendê materializado por territórios-rede do dendê. Baseamo-nos em entrevistas, coleta de dados, mapas e trabatho de campo levantados desde 2008 nos municípios de Moju, Acará, Tailândia, Tomé-Açu e Concórdia do Pará, lugares onde a monocultura da palma africana se expande e exige um olhar geográfico, atento aos usos e abusos do território.

Palavras-chave: Amazônia. Território. Camponês. Dendeicultura.

\section{The oil palm cultivation in the Brazilian Amazon region of Tomé-Açu, Pará}

\begin{abstract}
In this paper we analyze the expansion of oil palm cultivation in the micro-region of Tomé-Açu, in the Brazilian Amazon state of Pará. What landscape changes, in the spatial configuration, social dynamics, and utilized territory can we identify in this commodity boom? We begin by analyzing lands under oil palm cultivation, which lets us consider oil palm as a specific event and affirm that we are on the cusp of a oil palm boom being under taken by territorial networks of oil palm producers. We base this analysis in interviews, data collection, maps, and field work since 2008 in the municipalities of Moju, Acará, Tailândia, Tomé-Açu, and Concórdia do Pará, where African oil palm monocultures are expanding. This requires a geographic examination, attentive to the uses and abuses of the territory.
\end{abstract}

Keywords: Amazon. Territory. Peasant. Oil palm.

\section{Introdução}

As paisagens rurais dos municípios do Acará, Moju, Tailândia, Tomé-Açu e Concórdia do Pará, na microrregião de Tomé-Açu, no nordeste paraense, são marcadas por extensas monoculturas de dendê (Nahum; Malcher, 2012). Elas integram configurações espaciais estru- 
turadas a partir da ação estatal que, desde a década de 1950, quando introduziu essa cultura no campo paraense, cria condições econômicas, políticas, normativas e infraestruturais para viabilizar a reprodução da cadeia produtiva do óleo da palma no território paraense.

No nordeste paraense o cultivo do dendê para biodiesel constitui um evento, pois reorganiza a paisagem, a configuração territorial, a dinâmica social, enfim o espaço geográfico ou território usado (Nahum; Bastos, 2014). Segundo Veiga, Furlan Jr. e Kaltner (2005, p. 27) "o biodiesel [...] é o principal motivo do interesse atual pelo dendê". Desde então, temos demarcado um boom do dendê, tornado possível por determinados estágios das pesquisas tecnológicas acerca das condições edafoclimáticas necessárias e propícias ao cultivo em grande escala da palma do dendê; por um conjunto de ações governamentais que promoveram o cultivo da palma africana à política de Estado; por fim, pela voracidade do mercado de commodities de óleo de palma, que encontrou seus limites físicos e territoriais no continente asiático, por isso expande-se para África e América Latina.

Segundo o anuário estatístico do ministério da agricultura, pecuária e abastecimento (Brasil, 2011), em 1964, o Brasil produziu 84 mil toneladas de óleo de palma, mesma produção em 1974, em 1984, subiu para 29,9 mil toneladas. Número que saltou para 80,1 t/ano em 1994, 143,0 em 2004 (Brasil, 2011, p. 70). De acordo com o departamento de agricultura dos EUA, em 2014, estima-se que a produção de óleo de palma no Brasil alcançou 340 mil toneladas (Index Mundi, [s.d]).

Analisamos esse processo tendo como ponto de partida o território usado, isto é a área e seus usos (Gottmann, 1973; Sack, 1986; Santos; Silveira, 2001). Que transformações na paisagem, na configuração espacial, na dinâmica social, enfim, no território usado, podemos identificar nos lugares que vivenciam esse processo? Sustentamos nossa análise em viagens de campo feitas desde agosto de 2008 para Moju, Acará, Tailândia, Tomé-Açu, Concórdia do Pará, Garrafão do Norte, entre outros tantos lugares por onde a monocultura da palma africana se expande e exige um olhar geográfico, atento aos usos e abusos do território. Expomos alguns resultados construídos por meio de trabalho de campo, entrevistas e coleta de dados. Inicialmente discorremos sobre políticas de Estado que viabilizam o território para reprodução da cadeia produtiva do dendê, em seguida delineamos algumas modificações na paisagem, configuração espacial e dinâmica social estruturas a partir da formação dos territórios do dendê, por último as considerações finais.

\section{Políticas de Estado para o dendê}

A dendeicultura para biodiesel constitui um dos momentos mais enigmáticos de reprodução do capital no espaço agrário na Amazônia paraense, posto quereedita fatos e discursos típicos do ufanismo do I PDA (1972-74), que proclamava para a região a vocação de fronteira agrícola, produtora de alimentos e assim atraía o capital financeiro de bancos e mesmo multinacionais do setor automobilístico para o meio rural (Nahum, 2012). Segundo Müller, Furlan Jr. e Celestino Filho (2006), em 1980, foi aprovado, pelo Fundo de Investimentos Setoriais (Fiset) e o Instituto Brasileiro de Desenvolvimento Florestal (IBDF), o projeto da Reflorestadora da Amazônia S.A. (Reasa) para o plantio de 3.000 ha com dendezeiros e instalação de uma usina para processamento dos cachos. $\bigcirc$ projeto foi implantado no km-11,5 da estrada Moju-Acará 
(rodovia PA-252), município de Moju. Em 1990, ele foi adquirido, em parte, pela Marborges Agroindústria S.A. (Marborges). Em 1992, houve a instalação da usina de extração de óleo da Marborges, com capacidade para 9,0 t de cachos/hora.

No período atual, a dendeicultura na Amazônia paraense estrutura-se em políticas de Estado que atendem anseios do setor privado, sobretudo aqueles expressos em Políticas Públicas na agroindústria do dendê na visão do produtor (Veiga; Furlan Jr.; Kaltner, 2005). Esse documento da Embrapa caracteriza as versatilidades econômicas da dendeicultura

[...] que se presta não somente como matéria-prima para a indústria de alimentos como também na óleo-química, onde é utilizado em produtos de beleza e higiene; lubrificantes; sabões; detergentes e muitos outros [...] a alta produtividade faz da cultura do dendezeiro um candidato ideal para produção do biodiesel (Veiga; Furlan Jr; Kaltner, 2005, p. 10-11).

Aponta que na Amazônia:

[...] pelo menos 70 milhões de hectares [Acre, 2,5; Amapá 0,5; Amazonas 54; Pará 5,0; Rondônia 2,0; Roraima 4,0; Tocantins 1,0 [...] disponham de condições agroecológicas adequadas para o estabelecimento da palma (Veiga; Furlan Jr.; Kaltner, 2005, p. 12).

Expõe a situação da cultura do dendezeiro no Brasil, caracterizando seu enorme potencial (Veiga; Furlan Jr.; Kaltner, 2005, p. 13).

Em seguida, elenca fatores limitantes à expansão da palma como legislação ambiental, trabalhista, carga tributária e custo amazônico. Os autores entendem que "a legislação ambiental restritiva e equivocada, às vezes frontalmente oposta à expansão da agroindústria da palma, obrigando ao empresário rural a ser, antes de tudo, um guarda florestal, uma vez que deve preservar e cuidar da floresta nativa em 80\% de sua área" (Veiga; Furlan Jr.; Kaltner, 2005, p. 16). Esse percentual foi ratificado no Art. 12, da Lei n. 12.651/12, o novo código florestal, que trata da delimitação da área de reserva legal.

No entanto, de acordo com o parágrafo $5^{\circ}$ do Art. 12 do referido código,

Nos casos da alínea a do inciso I, o poder público estadual, ouvido o Conselho Estadual de Meio Ambiente, poderá reduzir a Reserva Legal para até 50\% (cinquenta por cento), quando o Estado tiver Zoneamento Ecológico-Econômico aprovado e mais de 65\% (sessenta e cinco por cento) do seu território ocupado por unidades de conservação da natureza de domínio público, devidamente regularizadas, e por terras indígenas homologadas.

Assim, na Amazônia Legal, um guarda florestal terá seu trabalho reduzido se o Estado fizer o Zoneamento Ecológico-Econômico, como determina o Art. 13 da Lei em foco:

Art. 13. Quando indicado pelo Zoneamento Ecológico-Econômico - ZEE estadual, realizado segundo metodologia unificada, o poder público federal poderá:

I - Reduzir, exclusivamente para fins de regularização, mediante recomposição, regeneração ou compensação da Reserva Legal de imóveis com área rural con- 
solidada, situados em área de floresta localizada na Amazônia Legal, para até 50\% (cinquenta por cento) da propriedade, excluídas as áreas prioritárias para conservação da biodiversidade e dos recursos hídricos e os corredores ecológicos;

Veiga, Furlan Jr. e Kaltner (2005) apontam ainda como fator limitante para expansão do dendê a ausência do Zoneamento Ecológico-Econômico (Veiga; Furlan Jr.; Kaltner, 2005. p, 16), mas hoje normatizado pelo Decreto n. 7.172 (Brasil, 2010b), que aprova o zoneamento agroecológico da cultura da palma de óleo e dispõe pelo Conselho Monetário Nacional de normas referentes às operações de financiamento ao segmento da palma de óleo, nos termos do zoneamento. Igualmente pelo projeto de Lei da Câmara n. 119 de 2013, que dispõe sobre a criação do Programa de Produção Sustentável da Palma de Óleo no Brasil e estabelece diretrizes para o zoneamento agroecológico para a cultura de palma de óleo e dá outras providências.

Os autores em foco apontam "o custo Amazônico, isto é, falta de infraestrutura básica e de apoio nas regiões distantes das cidades" (Veiga; Furlan Jr.; Kaltner, 2005, p. 17). O Programa de óleo de palma do estado do Pará tem por meta construir 676,27 quilômetros espalhados pela PA-252, PA-256, PA-151, PA-124, entre outras; seis pontes, abrangendo 1.949,88 m e cinco portos. Concretizando-se essa configuração espacial, provavelmente o custo Amazônico da cadeia produtiva do dendê será menor.

Programa de óleo de palma do estado do Pará é a tradução estadual do Programa Nacional de Produção e Uso do Biodiesel (PNPB) e do Programa de Produção Sustentável de Óleo de Palma (PSOP) que objetivam implementar a produção e uso de biodiesel de forma sustentável, com enfoque na inclusão social e no desenvolvimento regional, via geração de emprego e renda. Políticas que têm como principais diretrizes implantar um programa sustentável, promovendo inclusão social; garantir preços competitivos, qualidade e suprimento; produzir o biodiesel a partir de diferentes fontes oleaginosas e em regiões diversas.

Para tanto, o governo cria reserva de mercado por meio da Lei n. 11.097, de 13 de janeiro de 2005, que estabelece a obrigatoriedade da adição de um percentual de biodiesel ao óleo diesel comercializado ao consumidor, em qualquer parte do território nacional. $\bigcirc$ percentual obrigatório em 2012 alcançou 5\%, havendo um percentual obrigatório intermediário de $2 \%$ três anos após a publicação da mesma. A área plantada necessária para atender ao percentual de mistura de $2 \%$ de biodiesel ao diesel de petróleo é estimada em 1,5 milhões de hectares, o que equivale a 1\% dos 150 milhões de hectares plantados e disponíveis para agricultura no Brasil. Tecnicamente esse número não inclui as regiões ocupadas por pastagens e florestas. As regras permitem a produção a partir de diferentes oleaginosas (soja, algodão, palma, amendoim, girassol, mamona, entre outras) e rotas tecnológicas, possibilitando a participação do agronegócio e da agricultura familiar.

Responsável por regular e fiscalizar o novo produto, a Agência Nacional de Petróleo (ANP) cria a figura do produtor de biodiesel, estabelece as especificações do combustível e estrutura a cadeia de comercialização. A mistura do biodiesel ao diesel de petróleo é feita pelas distribuidoras de combustíveis, assim como na adição de álcool anidro à gasolina.

No PSOP, emerge a dendeicultura para energia, isto é, o cultivo de palma de dendê destinada à produção de biodiesel. Ele atrai empresas como a Biopalma, a Petrobras Biocombustível, ADM (Archer Daniels Midland), entre outras, para o espaço agrário regional. Processo 
que foi precedido pelo aquecimento no mercado de terras nos municípios da mesorregião do nordeste paraense em busca de áreas antropizadas, pois, segundo o Art. 4० do Programa "Fica vedada, a partir da vigência desta Lei, a supressão, em todo o território nacional, de vegetação nativa para a expansão do plantio de palma de óleo" (Brasil, 2010a).

Segundo o Decreto n. 7.172 (Brasil, 2010b), nos municípios da microrregião Tomé-Açu encontramos áreas preferencias e regulares para o cultivo do dendê. $\bigcirc$ Decreto aprova o zoneamento agroecológico da cultura da palma de óleo:

Considerando-se basicamente o cruzamento da aptidão climática com a aptidão das terras para o dendê, conferindo-se ênfase na interação entre solo e clima. Para avaliar a aptidão das terras para essa cultura, os fatores limitativos dos solos considerados representativos das condições agrícolas das terras são deficiência de fertilidade natural, deficiência de água, excesso de água e riscos de inundação, susceptibilidade à erosão, impedimentos ao desenvolvimento radicular, e impedimento à mecanização (Brasil, 2010b).

Trata-se de áreas antropizadas até 2007, pois antes a microrregião de Tomé-Açu conheceu outros produtos e atividades em função das quais reproduziu a dimensão espacial da vida cotidiana. A extração de madeira, pecuária extensiva, a cultura da pimenta, da mandioca, fruticultura, entre outras, possibilitaram aos municípios ter na agropecuária um forte setor de seu PIB, sempre associadas ao forte setor de serviços e ao fraco setor industrial, somados aos impostos e fundo de participação municipal, compunham o PIB (Homma; Menezes; Moraes, 2014; Rebello; Santos; Homma, 2011).

Antes do PNPB e do PSOP, o Grupo Agropalma praticamente monopolizava o agronegócio do dendê na microrregião de Tomé-Açu e seus produtos destinavam-se à indústria de alimentos. A partir destas políticas de Estado, sobretudo com o apoio do Decreto n. 7.172 (Brasil, 2010b), que aprova o zoneamento agroecológico da cultura da palma de óleo, a cultura do dendê é também promovida por empresas como Biopalma, Petrobras Biocombustível, a portuguesa Galp Energia, a multinacional ADM (Archer Daniels Midland Company) entre outras que se estabelecem na região. Isso porque o anexo do Decreto mostra que 23.276,73 $\mathrm{km}^{2}$ de área preferencial para o cultivo da palma, distribuídos por 53 municípios, e 69.999,88 $\mathrm{km}^{2}$ de área regular, distribuídos por 66 municípios.

$\bigcirc$ zoneamento reedita a ideia de espaço vazio e a ideologia da fronteira, como descritos em Nahum (2012). Na segunda década do século XXI, multinacionais como a Vale e a Petrobras, que, historicamente, tem seu foco em setores não agrícolas, orientam partes de seus recursos técnicos, humanos e financeiros para produção de óleo de palma de dendê utilizável na composição do biodiesel, edificando empresas como Biopalma, uma empresa Vale, e Petrobras Biocombustível. Políticos, empresários e comerciantes regionalmente conhecidos promoveram uma verdadeira varredura fundiária, mapeando imóveis rurais potencialmente qualificados para dendeicultura. Fazendas agropecuárias, sítios, chácaras, produtivos ou não, foram negociados, impulsionando o capital especulativo alicerçado na terra. $\bigcirc$ montante do capital especulativo aumentava quando a terra era revendida para os novos empreendedores da dendeicultura de energia. 
O mercado de terras cria condições territoriais para que a Biopalma, a Petrobras e a ADM adquiram terras para dendeicultura. A Biopalma, segundo o Basa (2012), tem por meta plantar 80 mil hectares, sendo $60 \mathrm{mil} / \mathrm{ha}$ próprios, praticamente adquiridos, e $20 \mathrm{mil} / \mathrm{ha}$ em associação com a agricultura familiar, abrangendo duas mil familias pelos municípios de Abaetetuba, Acará, Concórdia do Pará, Moju e Tomé-Açu. Considerando que a reserva legal a ser respeitada pelo dendê no estado do Pará, pois o mesmo tem Zoneamento Ecológico-Econômico, é de 50\% da área plantada, podemos dizer que a Biopalma terá o monopólio de uma área de $160 \mathrm{mil} / \mathrm{ha}$.

Para o Basa (2012), a Petrobras Biocombustível, tem dois grandes projetos de agricultura de energia. $\bigcirc$ projeto Belém Bioenergia S/A (BBB) em associação com a Galp Energia, que visa produção de óleo para Portugal. Ele prevê exportar 250 mil toneladas em 2014, abrangendo 50 mil/ ha em associação com agricultores familiares e produtores independentes. $\bigcirc$ outro projeto é o da Petrobras Pará, cuja meta é uma área de 48 mil/ha e abastecer a região Norte. A empresa não tem interesse em comprar terras, por isso estabelece parcerias, sobretudo arrendamento e programas de agricultores familiares. Concretizando-se essa meta a Petrobras Biocombustível terá o monopólio de uso do território de uma área de 98 mil ha e mais 98 mil ha de reserva legal, totalizando 196 mil ha.

De acordo com o Basa (2012), a ADM do Brasil iniciou em 2011, a construção de uma planta de processamento de palma no município de São Domingos do Capim, em parceria com produtores locais e o governo. A produção ocupará um total de 12.000 ha, sendo $50 \%$ próprio e a outra metade com a agricultura familiar (600 familias com plantio individual em torno de 10 há). A usina de processamento será implantada na comunidade Perseverança, município de São Domingos do Capim, com capacidade de 60 toneladas de cachos de frutos frescos por hora. Concretizando-se essa meta a empresa terá o monopólio de uso do território de uma área de 24 mil ha, considerada a reserva legal.

A expansão do dendê ressalta a histórica concentração de terra, que se tornou assunto esquecido, sufocado pelo discurso do desenvolvimento territorial rural, da geração de emprego e renda, da inclusão social, da recuperação de áreas degradadas pela pecuária. De modo que, na contabilidade das vantagens comparativas a concentração de terra aparece como um mal necessário e menor. Os territórios do dendê mostram a concentração e a centralização de terra em poucas empresas. Segundo o boletim do Basa (2012), a meta da Biopalma é 80 mil ha de plantio, partindo do pressuposto que o dendê tem 50 de reserva isso significa que então ela quer ter $160 \mathrm{mil} / \mathrm{ha}$. Somando a área das 112 propriedades (Brasil, [s.d.]), cujo cadastro ambiental rural está em nome dessa empresa, concluímos que ela está próxima de dessa meta, pois conta com $108.387,2889$ ha.

Formam-se território-rede do dendê, que explicitam a concentração e centralização de terras, reforçando que a estrutura agrária na Amazônia continua desigual, bem como a distribuição das políticas de Estado para o meio rural. Estas últimas continuam a conceber o campo como espaço econômico, espaço produtivo e setor econômico, que deve ser progressivamente mais rentável, cada vez menos habitado pelo camponês tradicional.

\section{Territórios do dendê}

As políticas estatais associadas aos interesses empresariais criam condições e possibilidades para formar territórios-rede do dendê (Nahum; Santos, 2013), os quais se distribuem predominantemente pela macrorregião do nordeste paraense, singularizando-se pela descon- 
tinuidade, configurando-se como territórios-rede (Haesbaert, 2004) espalhados pelo arranjo espacial do estado, onde cada campo de dendê constitui um ponto na rede, unificados por um comando exógeno. $\bigcirc$ tamanho e a número de pontos dependem da envergadura e da natureza do capital acionado para transformar extensas terras em território do dendê. Portanto, nem toda empresa de dendê tem condições políticas, econômicas e espaciais para construir seu território-rede, como ilustra o mapa abaixo.

Considerando os dados da Secretaria Estadual do Meio Ambiente do Estado do Pará, da Ouvidoria Agrária do Ministério Público Estadual e as informações das empresas e do trabalho de campo sobre a distribuição de empresas dendeicultoras no estado do Pará, podemos assinalar dois grandes períodos, antes e depois do PNPB. Até 1960 essa atividade era desenvolvida pela Denpasa, no município de Benevides, em Santa Izabel do Pará, Santo Antônio do Tauá, Benevides e Ananindeua pela empresa Codenpa, sendo as duas empresas estatais. Segundo estimativas do Ministério da Agricultura, Pecuária e Abastecimento (Brasil, 2011) e da FAO, apresentados no Anuário Estatístico de Agroenergia publicado pelo Mapa (Brasil, 2011, p. 69), nessa década a área plantada era de dois mil hectares.

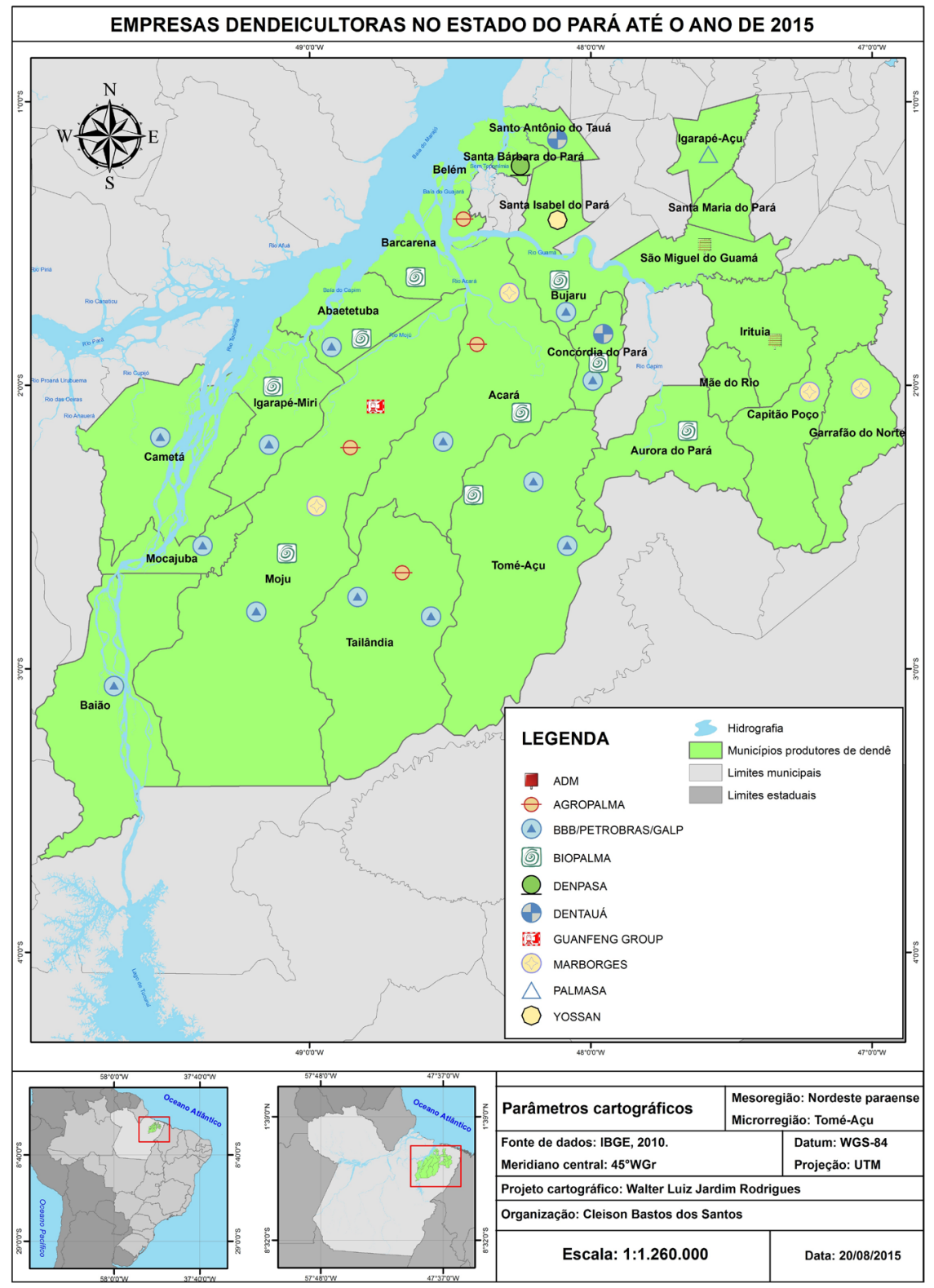


Observamos em 2015 a dendeicultura desenvolvida pelas empresas Marborges, Agropalma, Biopalma ou Biovale, Petrobras Biocombustível (Galp/BBB/Petrobras Biocombustível), Yossan, Repsol, Dentaua, Palmasa, ADM, Guanfeng Group, entre outras, distribuídas pelos municípios de Abaetetuba, Acará, Aurora do Pará, Baião, Bujaru, Cametá, Castanhal, Capitão Poço, Concórdia do Pará, Garrafão do Norte, Igarapé-Açu, Irituia, Mãe do rio, Mocajuba, Moju, São Domingos do Capim, Tailândia e Tomé-Açu. Considerando os dados da Secretaria de Agricultura do Estado do Pará (Sagri), em 2012, a área plantada de dendê no estado do Pará foi de 58.975 ha.

A expansão do dendê reorganiza a vida cotidiana de comunidades rurais como a da Forquilha em Tomé-Açu que se singularizava pelo envolvimento consigo mesmo, as relações sociais que lhes sustentam e estruturam eram predominantemente construídas no entorno, alicerçadas em unidades familiares que cultivavam, produziam, criavam e extraíam do território o necessário para a reprodução de suas vidas; o dinheiro ainda não era o principal mediador das relações de trabalho, prevaleciam laços de solidariedade orgânica e organizacional que alicerçavam mutirões e troca de dias de trabalho.

Esta dinâmica se estende até a metade do século XX, quando a abertura de estradas emerge sob o comando imperativo da ação estatal para reprodução do capital na Amazônia Oriental. Por essas vias transportaram-se pessoas e muitos componentes dos sistemas técnicos que edificaram Tucuruí, Carajás e Albrás/Alunorte, bem como escoam madeira, carvão e gado. Nas suas margens brotaram cidades do campo, agrovilas e muitos projetos de colonização emergiram. Seguindo a densidade, diversidade e intensidade do capital, a abertura de rodovias como BR-153, BR-158, BR-222, no sudeste paraense, PA-124, PA-127, PA-136, PA-140, no nordeste paraense, reinventaram municípios como Redenção, Santana do Araguaia, Marabá, São Geraldo do Araguaia, Dom Eliseu, Capanema, Igarapé-Açu, Castanhal, entre outros, tornando-se a principal via de circulação, o que não acontece com municípios como Juruti e Santarém, no oeste paraense, cuja circulação de pessoas, bens e serviços ainda subordina-se ao tempo dos rios e dos transportes hidroviários.

Na década de 1980, quando a dendeicultura se estabeleceu às margens da PA-150, ainda não era considerada política de Estado, assumindo essa forma no início do século XXI com o Plano Nacional de Produção e Uso do Biodiesel e do Programa da Palma, exigindo grandes extensões de terra para formar um arranjo espacial composto de plantios com diferentes idades, áreas de expansão, de reserva, viveiros, estradas e a infraestrutura da agroindústria que, entre outras, inclui um parque industrial, com máquinas, veículos, equipamentos e habitações para os recursos humanos.

A dinâmica dos lugares se altera. Em 2009, o simples "disse me disse", o boato localmente difundido de que haveria plantação de dendê que antecedeu a chegada da Biopalma, da Petrobras Biocombustível, da ADM (Archer Daniels Midland Company) nos municípios de Moju, Acará, Tailândia, Tomé-Açu e Concórdia do Pará foi o suficiente para fomentar especulação imobiliária, fluxos de capital e mão de obra, que independentemente de plantarem dendê em área legalmente permitida ou mesmo em terra ilegal, desencadeiam impactos socioambientais. O lugar torna-se des-envolvido, subordinado e dependente de comandos exógenos aos locais onde o complexo produtivo do dendê se implanta. 
Encontramos esse des-envolvimento na comunidade da Forquilha em Tomé-Açu na PA140, que de comunidade camponesa metamorfoseou-se, nos últimos cinco anos, em comunidade rural que tem sua reprodução alicerçada no circuito inferior da economia criado para atender de modo imediato às demandas dos assalariados do dendê. Em 2015, durante trabalho de campo, nos deparamos com uma configuração espacial marcada por setor de serviços típico de um circuito inferior da econômica (Santos, 2004) construído a partir de 2008, com a chegada da Biopalma para atender o consumo da mão de obra que trabalha nos campos de dendê da empresa.

\section{Tabela 1 - Evolução dos estabelecimentos comerciais na Vila Forquilha (2000-2015)}

\begin{tabular}{|c|c|c|c|c|c|c|c|c|c|c|}
\hline comércio/ano & 2000 & 2005 & 2008 & 2009 & 2010 & 2011 & 2012 & 2013 & 2014 & 2015 \\
\hline mat. construção & 1 & & 1 & & 1 & & & & & \\
\hline móveis e eletrodomésticos & & & & & & & 1 & 1 & 1 & \\
\hline calçados e roupas & & & & & & & 3 & 1 & & 1 \\
\hline restaurantes & & 2 & & & & 1 & & & & \\
\hline supermercado & & & 1 & & 1 & & & & & \\
\hline oficina de moto & & & 1 & & 1 & & & 1 & & \\
\hline informática & & & & 1 & & & & 1 & & \\
\hline posto de gasolina & & & & & 1 & & & & & \\
\hline distr. de bebidas & & & & & 1 & & & & & \\
\hline loja agrícola & & & & & & & 1 & & & 1 \\
\hline farmácia & 1 & 1 & & & & & & & & \\
\hline loja de variedade & & & & 1 & & & & & & \\
\hline
\end{tabular}

fonte: Pesquisa de campo do grupo GDEA, em agosto de 2015.

Nesta situação geográfica visualizamos nos lugares onde a dendeicultura aporta a tendência a descampesinização, isto é, formação de um campo sem camponeses, predominando moradores rurais, assalariados rurais ou mesmo produtores de dendê. Se quisermos, proletariza o camponês nos termos descritos por Kautsky (1986) sobre os impactos da indústria na vida do camponês:

Esse desenvolvimento que cria a demanda de assalariados, cria também o respectivo gênero de trabalhadores. Esse mesmo desenvolvimento proletariza muito o camponês, reduz sua família em como já vimos, ele também joga no mercado de trabalho os excedentes familiares, os filhos e filhas desse camponês. Enfim, ele produz entre os pequenos camponeses a necessidade de um rendimento suplementar além daquele que lhe fornece o estabelecimento agrícola de sua propriedade (Kautsky, 1986, p. 21).

Nos territórios do dendê desencadeiam-se processos de descampesinização. Senão vejamos, para concretizar suas metas a Biopalma deverá contar com um contingente de mão de obra de aproximadamente oito mil pessoas, sendo seis mil de mão de obra individual assalariada 
e duas mil unidades familiares, mão de obra coletiva, proveniente de associação com agricultura familiar; a Petrobras Biocombustível contará com a adesão de 98 mil unidades produtivas entre familiares e arrendatário; a ADM, por sua vez, para atingir sua meta terá a adesão de 600 unidades familiares e um contingente de 600 trabalhadores assalariados individuais.

Os números decorrem da contabilidade gerencial das empresas, segundo a qual, para ser lucrativo, o empreendimento deve manter o patamar de um trabalhador a cada 10 ha, ou seja, cada trabalhador e unidade familiar cuidará de 1.430 plantas. Isso torna o trabalho na dendeicultura profundamente exaustivo, pois desde a aquisição e transporte das mudas, preparo de área, plantio, tratos culturais, colheita, transporte até a agroindústria e processamento tudo demanda esforço físico.

Considerando os números do Basa acerca das operações e área financiada para agricultura familiar de dendê, as metas de inclusão social de unidades familiares por meio da dendeicultura de energia ainda estão demasiadamente distantes. Segundo documentos do Basa, no período de 2005 a 2009, temos 248 contratos do Pronaf no município de Moju e um em Tomé-Açu 1; números no intervalo de 2010 a 31 de julho de 2014 esses números saltam para 1.608 contratos distribuídos por 18 municípios.

A dendeicultura de energia não se sustenta do trabalhador coletivo das unidades familiares. Esse contingente é pequeno comparado ao número de trabalhadores individuais. Mas é importante componente do discurso de responsabilidade socioambiental, geração de emprego, renda e inclusão social, transformando o tradicional camponês em agricultor familiar associado à dendeicultura.

Segundo entrevista com funcionários da Biopalma e a gerência da Marborges, os altos índices de inadimplência, a ausência de arranjos institucionais locais junto às prefeituras, problemas com a regularização de imóvel, a inexistência de capital social camponês, além do hiato entre o número de famílias cadastradas no diagnóstico territorial participativo e àquelas aptas ao programa de agricultura familiar explicam pequeno número de contratos no Pronaf-ECO, linha de crédito destinada a custear projetos de agricultura familiar do dendê.

A unidade produtiva inserida nos programas de agricultura familiar tem a possibilidade de cultivar dendê consorciado com mandioca, melancia, feijão, por exemplo, mas somente no primeiro ano de plantio da palma, quando as raízes ainda não estão completamente desenvolvidas e permite o plantio de culturas que não são de raízes profundas. Entretanto, provavelmente, lhe faltaria energia física para essas atividades, visto que a mesma foi utilizada no empreendimento do dendê. Assim, a pluriatividade característica da unidade familiar camponesa, provavelmente, tende a ceder espaço para a especialização produtiva, predominando o que Bernstein (2011) chama de mercantilização da sobrevivência, ou seja, "[a] mercantilização é o processo pelo qual os elementos de produção e reprodução social são produzidos para troca no mercado e nele obtidos e que os sujeita às suas disciplinas e compulsões" (Bernstein, 2011, p. 125).

Em trabalho de campo realizado pela turma de geografia da UFPA, em agosto de 2013, nas unidades familiares que plantam dendê associadas à Biopalma em Tomé-Açu, os produtores ressaltaram que:

O cultivo do dendê é mais uma alternativa de produção boa, pois tem comprador certo. Mas é difícil para uma só pessoa trabalhar os 10 ha, ele precisa contar com a ajuda de vizinhos amigos. Só ele não dá. Além do que hoje nós compramos muitas coisas do que a gente plantava antes (informação verbal). 
Noutra entrevista ouvimos as vantagens e as dificuldades da associação com o dendê, como relata o entrevistado 2, que trabalha no terreno do sogro de 25 ha e plantou dendê em 10 ha.

Decidi plantar dendê por sua vida prolongada e alta produtividade, que nos primeiros anos é de $3 \mathrm{t} /$ ha e depois pode chegar a produzir $15 \mathrm{t} / \mathrm{ha}$, e também porque o terreno é muito úmido e, por isso, improdutivo para o plantio da mandioca (informação verbal).

O entrevistado 3 menciona que a familia deixou de cultivar outras culturas (pimenta e mandioca que produziam antes) para se dedicar ao dendê, ele trabalha sozinho no dendezal e não tem tempo de trabalhar no roçado. "Agora temos que comprar tudo o que antes eles produziam (feijão, arroz e farinha). Até o momento, a vida da família não melhorou, mas espero que no futuro melhore, estamos até pensando em voltar a produzir a cultura familiar" (informação verbal).

Apesar disso as unidades familiares são atraídas para a dendeicultura, pois as empresas oferecem apoio ao produtor tanto da porteira para dentro quanto da porteira para fora, seja na gestão dos créditos do Pronaf-ECO, na forma de alocação desses recursos para custeio e capital, seja prestando assistência técnica, treinamento, monitoramento, garantia de compra. Apoio que ele nunca conheceu na sua história de vida no campo. Ou melhor, o único "apoio" decorria do atravessador, responsável por escoar para o mercado produtos do campesinato tradicional. A dendeicultura não precisa da figura do atravessador, historicamente responsável pela circulação e comercialização dos produtos do camponês, visto que a precariedade infraestrutural da estrada, associadas à ausência de linhas regulares de transporte colocam o produtor rural refém dos atravessadores. A empresa torna-se o atravessador, mediador entre o produtor e o mercado.

As unidades familiares associadas aos projetos de agricultura familiar de dendê não perdem a propriedade jurídica da terra, e as pessoas tampouco se tornam assalariadas das empresas; em suma, continuam proprietárias da terra como meio de produção e força produtiva, e sua força de trabalho não é vendida à empresa. Porém, quem determina e comanda os usos dessa terra são as empresas; a terra, por meio de contratos entre partes "juridicamente iguais" e em comum acordo, transformou-se em território usado pelo dendê. Igualmente a força de trabalho de todos que adentram os campos é treinada, comandada e utilizada exclusivamente para a cultura da palma africana.

Estamos diante de um processo de descampesinização, um campo sem camponeses, paulatinamente impulsionado pela ausência de política de Estado para o campo, sobretudo para as comunidades rurais camponesas, redirecionando essa classe para reprodução de um modo de vida que não é o seu. Os camponeses tradicionais não dispõem de alternativa produtiva do mesmo suporte institucional capaz de se configurar como alternativa ao dendê. Nenhuma linha do Pronaf recebe tanto apoio e incentivo do Estado e do capital quanto o Pronaf-ECO, sobretudo no que se refere à garantia de compra do produto a preço de mercado e monitoramento de todas as fases do processo produtivo, a começar pelo piqueteamento da área, treinamento para coleta e mesmo carregamento da produção até a agroindústria. Mesmo as organizações representativas dos camponeses, agricultores familiares e trabalhadores rurais carecem de propostas alternativas à dendeicultura como pensamento único do desenvolvimento rural, da geração de emprego e de renda. Movimentam-se no mesmo campo político que reivindica 
a inclusão da agricultura familiar nos projetos de dendê como única política de Estado para o meio rural. Portanto assistimos, isto sim, à continuidade de um longo processo de formação de um campo sem camponeses, lentamente gestado por um Estado que secundariza a política agrária que prime pela reprodução do modo de vida do campesinato tradicional.

As políticas agrárias propostas até aqui são desenvolvimentistas e produtivistas, concebem o campo como um espaço econômico, um espaço para produção e não um espaço para viver, um exemplo é o Pronaf cuja meta é transformar o camponês tradicional em empreendedor rural. Provavelmente isso explica o êxodo rural, pois os usos do espaço agrário são viabilizados para a reprodução do capital, que se apropria de territórios historicamente usados por comunidades e campesinato tradicionais, que mantem com a terra uma relação de pertencimento, berço onde cultivam, criam, extraem e produzem as condições necessárias à produção de seu gênero de vida.

Busca-se nos territórios do dendê emprego e renda, abandona-se a unidade produtiva familiar camponesa, forma-se um campo sem camponeses, posto que estes se metamorfoseiam, paulatinamente, em trabalhadores para o capital (Wanderley, 2009). Esse movimento acentua processos anteriormente existentes nesses espaços rurais tais como a crise na produção familiar de alimentos, envelhecimento do agricultor familiar, enfraquecimento da pluriatividade no campo, dependência e subordinação dos lugares à dinâmica das empresas, enfraquecimento dos movimentos sociais e das lutas pela reforma agrária, entre outros que são objeto de investigação, análise e interpretação da geografia agrária e dos movimentos sociais. Foge aos limites deste texto elucidar como, porquê, quando e onde a dendeicultura aprofunda esses processos.

\section{Considerações finais}

○ espaço agrário tem múltiplas possibilidades, sobretudo se concebido numa perspectiva territorial, consideradas a configuração espacial e as dinâmicas sociais. Espaço caracterizado pelo uso da terra como principal força produtiva e meio de produção por diferentes e divergentes grupos e classes sociais, uns concebendo-o eminentemente como setor produtivo da economia, outros como lugar singularizado por seu modo de vida, o campo é palco, produto e condicionante de lutas entre classes sociais para territorializar seus interesses, isto é, seus usos do território.

Em se tratando do espaço amazônico oriental, não cremos no messianismo redentor da monocultura do dendê que promete sustentabilidade ambiental, rentabilidade econômica, inclusão social de agricultores familiares, soberania e segurança energética e alimentar, sem que se esclareça para quem e como. Trata-se, isto sim, de mais um capítulo da questão agrária na Amazônia, em que as virtudes de um produto (drogas do sertão, borracha, manganês, ferro, bauxita, energia e gado) são insuficientes para assegurar espaços menos desiguais e mais justos. Formam-se verdadeiros processos de des-envolvimento de comunidades rurais tradicionais, campos descampesinizados, espaços mais e mais esquizofrênicos, posto que organizados segundo comandos exógenos, e não daqueles que cotidianamente os vivem.

A dendeicultura não é a solução nem a causa dos males que afligem o espaço agrário nas áreas antropizadas. É preciso superar a tradição política que subordina o desenvolvimento da Amazônia à ascensão ou à queda de um produto no mercado mundial, no qual se depositam todas as esperanças, política que se ufana ao dizer "nossos minérios", "nossa floresta", "nossas 
riquezas" ou que repete o mito do desenvolvimento em muitos adjetivos - regional, sustentável, territorial, participativo -, esquecendo-se de perguntar quem usufrui dessas riquezas, sejam elas essências florestais, borracha, madeira, minérios, energia hidroelétrica ou dendê. Dendê para quem? Por quê? Para quê?

Portanto, é preciso perguntar quem ganha com a dendeicultura, pois tão importante quanto ressaltar suas potencialidades econômicas, ambientais e sociais, é refletir sobre quem usufrui dos dividendos dessas potencialidades, ou seja, quem fica com a renda da terra e se beneficia do território; refletir sobre os impactos no modo de vida do lugar onde o agronegócio do dendê se implanta e expande, isto é, sobre o que significa passar da condição de lavrador para agricultor de dendê ou, de outro modo, de camponês tradicional para agricultor familiar do dendê, trabalhador para o capital.

\section{Referências}

BASA. BANCO DA AMAZÔNIA. A experiência do banco da Amazônia com projetos integrados de dendê familiar. Contexto amazônico, v. 22, n. 5, p. 1-8, 2012. Disponível em: <http://www.bancoamazonia.com.br/images/arquivos/institucional/biblioteca/ boletim/contexto_amazonico_22.pdf>. Acesso em: 10 set. 2016.

BERNSTEIN, H. Dinâmicas de classe da mudança agrária. São Paulo: Unesp, 2011.

BRASIL. Ministério da Agricultura, Pecuária e Abastecimento. Anuário estatístico da agroenergia 2010. 2. ed. Brasília, DF: Mapa/ACS, 2011. Disponível em: <http:// www.agricultura.gov.br/arq_editor/file/Desenvolvimento_Sustentavel/Agroenergia/ anuario_agroenergia/>. Acesso em: 24 out. 2014.

BRASIL. Projeto de Lei n. 7.326-C, de 2010. Dispõe sobre a criação do Programa de Produção Sustentável da Palma de Óleo no Brasil, estabelece diretrizes para o zoneamento agroecológico para a cultura de palma de óleo, e dá outras providências. Poder Executivo, Brasilia, DF, 13 maio 2010a. Disponível em: <http://www.camara.gov.br/proposicoesWeb/prop_mostrarintegra;jsessionid=D65D1D1B330F66B1E7296BF3E4FCF0E7. proposicoesWebExterno2? codteor $=768113$ Efilename $=P L+7326 / 2010>$. Acesso: 25 nov. 2016

BRASIL. Decreto n. 7.172, de 7 de maio de 2010. Aprova o zoneamento agroecológico da cultura da palma de óleo e dispõe sobre o estabelecimento pelo Conselho Monetário Nacional de normas referentes às operações de financiamento ao segmento da palma de óleo, nos termos do zoneamento. Brasilia, DF, 7 maio 2010b. Disponível em: <http:// www.planalto.gov.br/ccivil_03/_Ato2007-2010/2010/Decreto/D7172.htm>. Acesso em: 18 set. 2015 .

BRASIL. Secretaria de Estado de Meio Ambiente e Sustentabilidade. Governo do Pará. Simlam, [s.d]. Disponível em: <http://monitoramento.semas.pa.gov.br/simlam/index. htm>. Acesso em: 18 set. 2015.

GOTTMANN, J. The Significance of Territory. The University Press of Virginia: Charlottesville, 1973. 
HAESBAERT, R. O mito da desterritorialização: do "fim dos territórios" à multiterritorialidade. Rio de Janeiro: Bertrand Brasil, 2004.

HOMMA, A. K. O.; MENEZES, A. J. E. A.; MORAES, A. J. G. Dinâmica econômica, tecnologia e pequena produção: o caso da Amazônia. In: BUAINAIN, A. M. et al. O mundo rural no Brasil do século 21. Brasília-DF: Embrapa, 2014. p. 981-1010.

INDEX MUNDI. Palm oil production by country in 1000 MT. [s.d]. Disponível em: <http:// www.indexmundi.com/agriculture/?commodity=palm-oilE $>$. Acesso em: 18 set. 2015.

KAUTSKY, K. A questão agrária. São Paulo: Nova Cultural, 1986.

MÜlleR, A. A.; FURLAN JR., J.; CELESTINO FILHO, P. A Embrapa Amazônia Oriental e o Agronegócio do Dendê no Pará. Belém, PA: Embrapa Amazônia Oriental, 2006.

NAHUM, J. S. Região e representação: a Amazônia nos planos de Desenvolvimento. In: Biblio 3W - Revista Bibliográfica de Geografía y Ciencias Sociales, Barcelona, v. XVII, n. 985, 25 jul. 2012. Disponível em: <http://www.ub.edu/geocrit/b3w-985. htm>. Acesso em: 24 out. 2014.

; BASTOS, C. S. Dendeicultura e descampesinização na Amazônia paraense. Campo-Território - Revista de Geografia Agrária, Uberlândia, v. 9, n. 17, p. 469485, abr. 2014. Disponível em: <http://www.seer.ufu.br/index.php/campoterritorio/ issue/view/1113>. Acesso em: 24 out. 2014.

; MALCHER, A. T. Dinâmicas territoriais do espaço agrário na Amazônia: a dendeicultura na microrregião de Tomé-Açu, PA. Confins, n. 16, 2012. Disponível em: $<$ http://confins.revues.org/7947?lang=pt>. Acesso: 24 out. 2014.

; SANTOS, C. B. Impactos socioambientais da dendeicultura em comunidades tradicionais na Amazônia paraense. ACTA Geográfica, Boa Vista-RR, p. 63-80, 2013. Edição Especial Geografia Agrária. Disponível em: <http://revista.ufrr.br/index.php/ actageo/issue/view/117/showToc >. Acesso em: 24 out. 2014.

REBELLO, F. K.; SANTOS, M. A. S.; HOMMA, A. K. O. Modernização da agricultura nos municípios do nordeste paraense: determinantes e hierarquização no ano de 2006. Revista de Economia e Agronegócio, v. 9, n. 2, 2011. Disponível em: <http://www. revistarea.ufv.br/index.php/rea/article/view/184>. Acesso em: 29 out. 2014.

SACK, R. D. Human Territorialit: Its theory and history. Cambridge: Cambridge University Press, 1986.

SANTOS, M. O espaço dividido. São Paulo: Edusp, 2004.

; SILVEIRA, M. L. Brasil: território e sociedade no início do século XXI. Rio de Janeiro: Record, 2001.

VEIGA, A. S.; FURLAN JR., J.; KALTNER, F. J. Políticas Públicas na agroindústria do dendê na visão do produtor. Belém, PA: Embrapa Amazônia Oriental, 2005.

WANDERLEY, M. N. B. O mundo rural como um espaço de vida. Reflexões sobre a propriedade da terra, agricultura familiar e ruralidade. Porto Alegre-RS: Editora da UFRGS, 2009. 